\title{
Reverse-phase HPLC Separation of D-Amygdalin and Neoamygdalin and Optimum Conditions for Inhibition of Racemization of Amygdalin
}

\author{
Eun-Young Hwang, ${ }^{a}$ Je-Hyun LeE, ${ }^{a}$ Yong-Moon LeE, ${ }^{b}$ and Seon-Pyo Hong ${ }^{*, a}$ \\ ${ }^{a}$ Department of Oriental Pharmaceutical Sciences, Kyung Hee University; Dongdaemoon-gu Hoegi-dong \#1, Seoul \\ 130-701, Korea: and ${ }^{b}$ College of Pharmacy, Chungbuk National University; Chongju 361-763, Korea. \\ Received April 11, 2002; accepted June 29, 2002
}

\begin{abstract}
In boiling aqueous solution, D-amygdalin usually begins to convert into neoamygdalin in 3 min and more than $30 \%$ of the initial D-amygdalin is found as neoamygdalin after $30 \mathrm{~min}$. In this report, we establish methods for simple HPLC analysis and the inhibition of D-amygdalin conversion. D-Amygdalin and its conversion product, neoamygdalin, were clearly separated on reverse-phase column chromatography by an optimized eluent of $10 \mathrm{~mm}$ sodium phosphate buffer ( $\mathrm{pH}$ 3.8) containing $6 \%$ acetonitrile. Linearity for analyzing D-amygdalin and neoamygdalin was observed in the range from 0.05 to $0.5 \mathrm{~mm}$. The detection limits for D-amygdalin and neoamygdalin were $c a .5 \mu_{\mathrm{M}}$ per injected amount. We found that D-amygdalin conversion was completely inhibited by adding $0.05 \%$ citric acid to the aqueous solution before boiling. To prevent the loss of pharmaceutical potency of Tōnin, we applied this method to measure the conversion rate of D-amygdalin. We confirmed that D-amygdalin conversion in Tōnin is effectively inhibited by acidic boiling solution with $0.1 \%$ citric acid.
\end{abstract}

Key words D-amygdalin; neoamygdalin; high-performance liquid chromatography; Tōnin; Persicae Semen; racemization

There have been many studies on the antitumoral effect of D-amygdalin (D-mandelonitrile- $\beta$-D-gentiobioside), generally known as Laetrile. ${ }^{1-3)}$ It was reported that D-amygalin in aqueous solution is racemized to neoamygdalin (L-mandelonitrile- $\beta$-D-gentiobioside), making it ineffective against cancer. ${ }^{4}$ Therefore it is necessary to examine the optimum conditions for prevention of racemization. We found that it was important to separate isoamygdalins completely to determine the index for the degree of inhibition of racemization. Many researchers have made an effort to separate isomers of amygdalin. The separation of isoamygdalin by gas chromatography ${ }^{5)}$ and capillary electrophoresis ${ }^{6}$ was good enough to be used as a practical analytical method. Until now, attempts to separate isoamygdalins using HPLC were reported, but the baseline resolution of D-amygdalin and neoamygdalin was not obtained. ${ }^{7-9)}$ We developed a reversephase HPLC method using a C18 column to separate Damygdalin and neoamygdalin to baseline resolution.

Traditional Oriental preparations are generally decocted with boiling water. A large portion of D-amygdalin is converted to neoamygdalin or destroyed with boiling. Therefore to overcome these problems, we established the optimum conditions for inhibiting the conversion to neoamygdalin by changing the $\mathrm{pH}^{4}{ }^{4}$ On the basis of these results, we applied the method to Tōnin (Persicae Semen) generally used in Oriental preparations and established the optimum conditions for inhibiting the conversion to neoamygdalin of D-amygdalin in Tōnin.

\section{Experimental}

Materials D-Amygdalin was obtained from Tokyo Kasei Chemical Co. (Tokyo, Japan). Acetonitrile was of HPLC grade. All other chemicals were of analytical reagent grade. Persicae Semen was purchased from a market in Chung Buk province, Korea, and the quality met that officially approved in the Korean Pharmacopoeia VII.

Apparatus and Chromatographic Conditions The HPLC systems used were a M930 pump (Young Lin, Kyunggi, Korea) with an M720 UV detector (Young Lin) set at $214 \mathrm{~nm}$. The column used was a Capcell Pak C18 UG120 ( $4.6 \mathrm{~mm} \times 250 \mathrm{~mm}, 5 \mu \mathrm{m}$, Shiseido, Tokyo, Japan). The column flow rate was $1 \mathrm{ml} / \mathrm{min}$. The mobile phase was a $10 \mathrm{~mm}$ sodium phosphate buffer (pH 3.8) containing 1-butanol or acetonitrile.
${ }^{1} \mathrm{H}-\mathrm{NMR}$ spectra were recorded by using a Bruker Avance-600 (600 MHz) NMR spectrometer and FAB-HR spectra were recorded using a JMSAX505WA mass spectrometer.

Sample Preparation Neoamygdalin was prepared from D-amygdalin and aqueous ammonia as described by Fischer. ${ }^{10)} \mathrm{D}$-Amygdalin was added to $10 \mathrm{ml}$ of $0.005 \mathrm{M}$ ammonia solution and the mixture was stored for $2 \mathrm{~h}$ at room temperature. During this period, D-L isomerization occured and equilibrium between D-amygdalin and neoamygdalin was achived.

Neoamygdalin was purified by HPLC (Nucleosil 100-5 C18, $250 \mathrm{~mm} \times 10$ $\mathrm{mm}$ i.d.; mobile phase, $6 \%$ acetonitrile; flow rate, $5 \mathrm{ml} / \mathrm{min}$; column temperature, ambient) and characterized by FAB-HR mass and ${ }^{1} \mathrm{H}-\mathrm{NMR}\left(\mathrm{CD}_{3} \mathrm{OD}\right)$ spectroscopy. ${ }^{6,7)}$ The molecular weights of D-amygdalin and neoamygdalin by FAB-HR mass spectroscopy were $458.1672[\mathrm{M}+1]$ and $458.1674[\mathrm{M}+$ 1], respectively. Proton NMR provides evidence of the presence of epimers by two distinctly different methine chemical shift values $(5.89 \mathrm{ppm}$ for Damygdalin and $6.07 \mathrm{ppm}$ for neoamygdalin).

Solutions containing amygdalin $(0.6 \mathrm{mg} / \mathrm{ml})$ in distilled water were prepared and heated at $100^{\circ} \mathrm{C}$ for 3,30 , and $120 \mathrm{~min}$. Solutions containing amygdalin $(0.6 \mathrm{mg} / \mathrm{ml})$ in $0.001 \%$ citric acid (measured $\mathrm{pH}$ of the solution: 5.9) and $0.05 \%$ citric acid $(\mathrm{pH} 4.3)$ were prepared and heated at $100{ }^{\circ} \mathrm{C}$ for $120 \mathrm{~min}$. Samples of Tōnin (Persicae Semen) containing $0.001 \%$ citric acid, $0.05 \%$ citric acid, and $0.1 \%$ citric acid were prepared and heated at $100^{\circ} \mathrm{C}$ for 120 min under reflux.
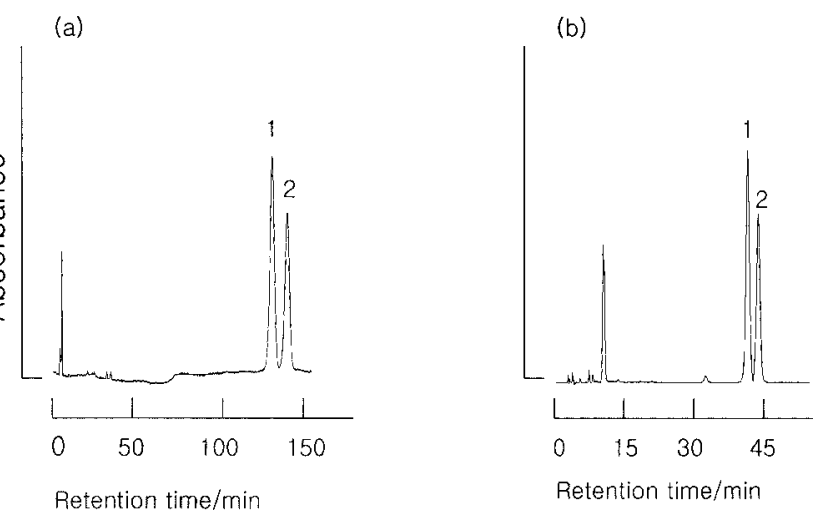

Fig. 1. Reverse-phase Separation of D-Amygdalin and Neoamygdalin by Phosphate Buffer Containing 1-Butanol or Acetonitrile

(a) $0.3 \%$ butanol, (b) $6 \%$ acetonitrile. 1 , neoamygdalin; 2 , D-amygdalin. 


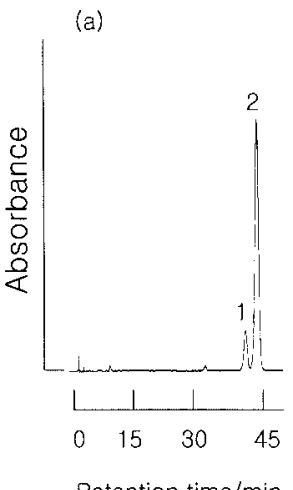

Retention time/min (b)

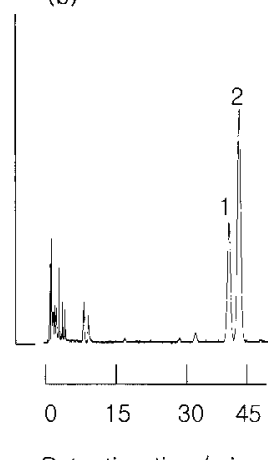

(c)

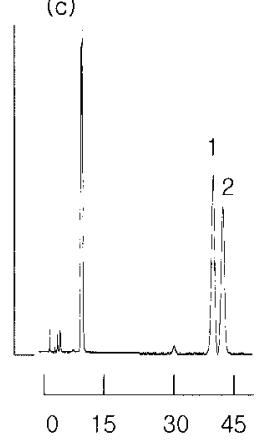

Retention time/min

Fig. 2. Degree of Conversion of D-Amygdalin to Neoamygdalin with Time of Heating in Boiling Water

(a) Heating time, $3 \mathrm{~min}$; (b) heating time, $30 \mathrm{~min}$; (c) heating time, $120 \mathrm{~min}$. 1, neoamygdalin; 2, D-amygdalin.

\section{Results and Discussion}

Separation of D-Amygdalin and Neoamygdalin The conditions of the mobile phase to separate D-amygdalin and neoamygdalin by reverse-phase HPLC were examined in 10 mM sodium phosphate buffer $(\mathrm{pH} 3.8)$ containing 1-butanol or acetonitrile. Complete baseline resolution was obtained using phosphate buffer containing $0.3 \%$ 1-butanol, but it had the shortcoming of requiring $135 \mathrm{~min}$ for separation (Fig. 1a). The separation time became shorter by increasing the concentration of 1-butanol, but baseline resolution was not obtained.

When phosphate buffer containing $6 \%$ acetonitrile was used instead of 1-butanol, baseline resolution was obtained and the separation time was shortened to 45 min (Fig. 1b). Therefore it appeared that $10 \mathrm{~mm}$ sodium phosphate buffer (pH 3.8) containing 6\% acetonitrile was a suitable mobile phase and it was used it for the separation of D-amygdalin and neoamygdalin. The calibration plots were drawn and showed a linear range of the UV response to the concentration $(0.05$ to $0.5 \mathrm{~mm})$ of D-amygdalin and neoamygdalin $\left(r^{2}\right.$ values were 0.9998 for $\mathrm{D}$-amygdalin and 0.9994 for neoamygdalin).

The detection limits were within $5 \mu \mathrm{M}(S / N=3)$.

Racemization of D-Amygdalin by Heating We investigated the degree of conversion of D-amygdalin to neoamygdalin with the addition of boiling water. As shown in Fig. 2, D-amygdalin started to convert to neoamygdalin $3 \mathrm{~min}$ after heating. About $30 \%$ and more than $50 \%$ of D-amygdalin, respectively, were converted to neoamygdalin 30 and $120 \mathrm{~min}$ after heating reaction. It was found that D-amygdalin in aqueous solution was converted to neoamygdalin by heating alone. Because only D-amygdalin is effective against cancer, it was necessary to determine the conditions for inhibition of its conversion to neoamygdalin.

Inhibition of the Conversion of D-Amygdalin to Neoamygdalin with Citric Acid Citric acid and ascorbic acid were examined to investigate whether they could inhibit the conversion of D-amygdalin to neoamygdalin. Citric acid, but not ascorbic acid, completely inhibited racemization. We examined the extent of the conversion to neoamygdalin in $0.001-0.5 \%$ citric acid solution at $100{ }^{\circ} \mathrm{C}$ for $2 \mathrm{~h}$. Figure 3 shows the results of $0.001 \%$ and $0.05 \%$ citric acid solution. Although the conversion rate was more than $50 \%$ in $0.001 \%$ citric acid solution ( $\mathrm{pH} 5.9$ ), the conversion rate to neoamyg-
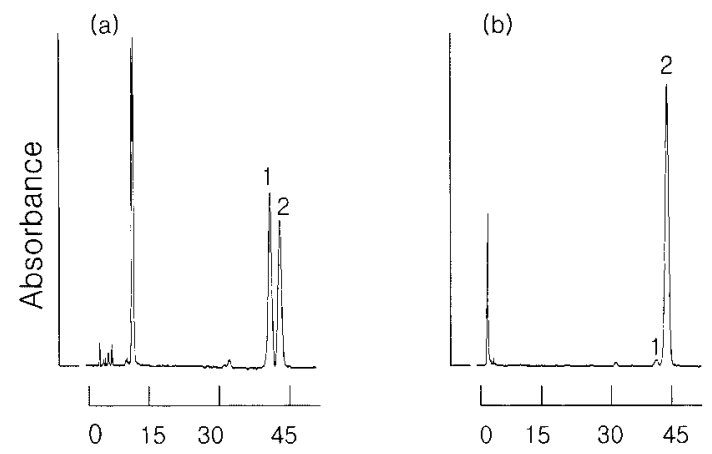

Retention time/min

Retention time/min

Fig. 3. Inhibition of Conversion to Neoamygdalin with the Amount of Citric Acid

(a) $0.001 \%$ citric acid, (b) $0.05 \%$ citric acid. 1 , neoamygdalin; 2 , D-amygdalin.

dalin in $0.05 \%$ citric acid solution $(\mathrm{pH} 4.3)$ were almost $0 \%$. Therefore $0.05-0.5 \%$ citric acid solution prevent the conversion and glycolysis of D-amygdalin.

Application to Natural Products In this study, we established methods to separate D-amygdalin and neoamygdalin and to inhibit racemization. We applied these methods to the extraction process of D-amygdalin from Tōnin (Persicae Semen), which is widely used in Oriental preparations. Figure 4 shows the inhibitory effects on the conversion to neoamygdalin with the percentage concentration of citric acid. The conversion rate to neoamygdalin in $0.005 \%$ citric acid solution ( $\mathrm{pH} 5.7)$ and $0.05 \%$ citric acid solution $(\mathrm{pH}$ 4.7 ) was about $20 \%$ and $10 \%$, respectively.

In $0.05 \%$ citric acid solution, racemization of standard amygdalin was completely inhibited, but that of the amygdalin in Tōnin was not completely inhibited because of the increase in $\mathrm{pH}$ due to various other constituents in Tōnin. The conversion rate to neoamygdalin in $0.1 \%$ citric acid solution ( $\mathrm{pH} 2.9$ ) was almost $0 \%$. About one-tenth of D-amygdalin is in the form of neoamygdalin as shown in Fig. 4c. The neoamygdalin originates from the native source of Tōnin, as confirmed by the existence of neoamygdalin in cold methanol extract. If neoamygdalin did not occur in nature, no neoamygdalin would be present in the cold extract. Therefore $0.1-0.5 \%$ citric acid solution can prevent the conversion and glycolysis of D-amygdalin when D-amygdalin is extracted from Tōnin. 
(a)

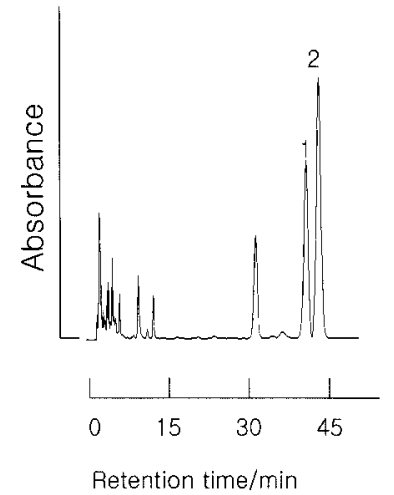

(b)

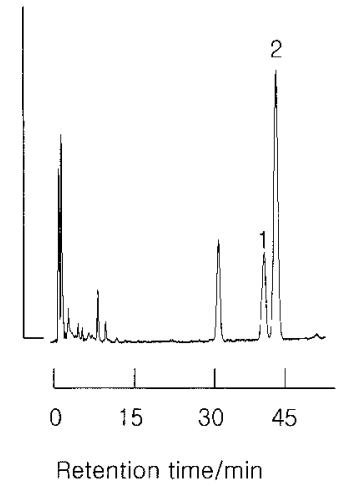

(c)

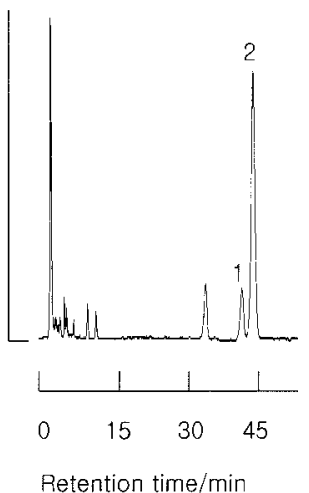

Fig. 4. Inhibitiory Effects on the Conversion to Neoamygdalin with the Amount of Citric Acid When Extracting Amygdalin from Tōnin (a) $0.005 \%$ citric acid, (b) $0.05 \%$ citric acid, (c) $0.1 \%$ citric acid. 1 , neoamygdalin; 2, D-amygdalin.

Acknowledgments This study was supported by a Brain Korea 21 Grant from the Korean Ministry of Education and the Research Fund of Kyung Hee University.

\section{References}

1) Culliton B. J., Science, 182, 1000-1001 (1973).

2) Stobaugh J. E., Sternson L. A., Repta A. J., Anal. Lett., 9, 753-764 (1978).

3) Zucker M., Let's Live, 65, 65 (1979).
4) Takayama Y., Kawai S., Chem. Pharm. Bull., 32, 778-781 (1984).

5) Takayama Y., Kawai S., J. Chromatogr., 197, 240-245 (1980).

6) Isozaki T., Matano Y., Yamamoto K., Kosaka N., Tani T., J. Chromatogr. A, 923, 249-254 (2001).

7) Cairns T., Froberg J. E., Gonzales S., Langham W. S., Stamp J. J., Howie J. K., Sawyer D. T., Anal. Chem., 50, 317-322 (1978).

8) Smith D. J., Weber J. D., J. Chromatogr. Sci., 22, 94-98 (1984).

9) Dybowski R., Anal. Proc., 18, 316-318 (1978).

10) Fischer E., Ber. Deut. Chem. Ges., 28, 1508 (1895). 